\begin{tabular}{cc|c}
\hline Tar. Bil. Der. & Tarm Bilimleri Dergisi & Journal of Agricultural Sciences \\
& $\begin{array}{c}\text { Dergi web sayfası: } \\
\text { www.agri.ankara.edu.tr/dergi }\end{array}$ & Journal homepage: \\
& www.agri.ankara.edu.tr/journal
\end{tabular}

\title{
Effects of Cultural Conditions on Exopolysaccharide Production by Bacillus sp. ZBP4
}

\author{
Erdi ERGENE ${ }^{\mathrm{a}}$, Ayşe AVCI ${ }^{\mathrm{b}}$ \\ ${ }^{a}$ Istanbul Esenyurt University, Faculty of Health Sciences, Department of Nutrition and Dietetics, 34510, Esenyurt, Istanbul, TURKEY \\ ${ }^{\boldsymbol{b}}$ Sakarya University, Faculty of Engineering, Department of Food Engineering, 54187, Serdivan, Sakarya, TURKEY
}

\section{ARTICLE INFO}

Research Article DOI: 10.15832 /ankutbd.456666

Corresponding Author: Ayşe AVCI, E-mail: aysea@sakarya.edu.tr, Tel: +90 (264) 2955464

Received: 20 February 2016, Received in Revised Form: 03 February 2017, Accepted: 08 February 2017

\begin{abstract}
Microbial exopolysaccharides (EPSs) are of great interest for the application in various industries due to their gelling, stabilizing, emulsifying, and antioxidant properties. In the present study, EPS production of 12 Bacillus strains were investigated and the best producer, namely Bacillus sp. ZBP4, was selected for further studies in order to determine the effects of fermentation conditions on the biosynthesis of EPSs. Beet molasses was used as substrate in the experiments. The highest amount of EPS was obtained at $60 \mathrm{~g} \mathrm{~L}^{-1}$ molasses concentration within $24 \mathrm{~h}$. Optimum temperature and $\mathrm{pH}$ were determined as $45^{\circ} \mathrm{C}$ and 5.0, respectively. Various carbon sources (glucose, starch, lactose, whey, mannitol, sucrose, beet molasses) have been tested for EPS production and beet molasses was found as the best. Using inorganic nitrogen source (ammonium sulfate) caused a decrease in the production of EPS. Tryptone gave the highest EPS yields amongst the organic nitrogen sources (yeast extract, peptone, tryptone) tested. Considerable increase in EPS production (1071 $\mathrm{mg} \mathrm{L}^{-1}$ ) has been observed when the experiment was conducted under the optimized conditions (using tryptone and $60 \mathrm{~g} \mathrm{~L}^{-1}$ molasses at $\mathrm{pH} 5.0$ and $45^{\circ} \mathrm{C}$ in $24 \mathrm{~h}$ ) which was $143 \mathrm{mg} \mathrm{L}^{-1}$ before the optimization studies.
\end{abstract}

Keywords: Bacillus; Exopolysaccharide (EPS); Beet molasses

\section{Introduction}

A group of microorganisms including the strains of bacteria, yeast and molds, are able to secrete high molecular weight polymers into their surroundings called as exopolysaccharide (EPS) (Koçberber \& Dönmez 2008; Fang et al 2013). Microorganisms produce EPSs as a response to harsh conditions in order to prevent cell damage (Donot et al 2012). Main structures of EPSs are comprised of monosaccharides, particularly glucose, galactose and rhamnose (Welman et al 2003). The interest in EPSs have increased considerably in the recent years, because of their physiological, chemical and rheological properties which make them suitable for a wide range of commercial applications in different fields, such as food, petroleum, cosmetics, textile, bioremediation and pharmaceuticals (Freitas et al 2011; Singh et al 2011; Öztürk et al 2014; Zhou et al 2014).

Even though numerous microorganisms can secrete EPSs, bacteria are considered as the best producers owing to the quality and quantity of EPSs 
(Kumar 2012). During the recent decades several Bacillus strains reported to produce EPSs, such as B. licheniformis (Sing et al 2011), B. subtilis (Shih et al 2010) and B. firmus (Salehizadeh \& Shojaosadati 2003). Levan is the best known EPS produced by Bacillus sp. which is mainly produced from sucrose. It is highly soluble in water, and has biological activity (e.g: anti-tumor and anti-inflammatory). It can be applied in food, feed, medicine, and cosmetics (Freitas et al 2011; Donot et al 2012).

The yield and the composition of EPSs produced by microorganisms are mainly dependent on the cultural conditions such as temperature, $\mathrm{pH}$ and medium composition (Tallon et al 2003; Çelik et al 2008). Sugars are mostly used for the production of EPSs as carbon source. However, there are researches concerning the utilization of cheaper carbon sources, generally agro-industrial wastes or by-products (Göksungur et al 2004; Freitas et al 2011). Molasses is a by-product of sugar industry either from the sugar cane or sugar beet. In Turkey, sugar industry relies on beet, hence beet molasses is readily available and the most preferred substrate in the fermentation industry. It has high sugar content (approximately 50\%) that can be fermented by yeasts and bacteria. In addition, it contains nitrogen, vitamins and minerals which support fermentation (Yilmaz et al 2012; Abdul Razack et al 2013).

The aims of the current study were; a) to investigate the EPS production capabilities of some Bacillus strains that were isolated from various food and soil samples, b) after selecting the best EPS producing isolate, to produce EPS using molasses by this strain (Bacillus sp. ZBP4) and c) to determine effects of process conditions (temperature, $\mathrm{pH}$ and substrate concentration) and some nitrogen and carbon sources on the EPS production.

\section{Material and Methods}

\subsection{Material}

Molasses was obtained from Adapazarı Sugar Factory in the 2014 season. Nutrient agar, nutrient broth, trichloroacetic acid (TCA), phenol, yeast extract, peptone, and tryptone were purchased from Merck (Darmstadt, Germany) and 3,5-dinitrosalycylic acid (DNS) was purchased from Sigma (USA).

\subsection{Cultural conditions and selection of EPS producing microorganisms}

The isolates which were maintained in nutrient broth containing $50 \%$ glycerol at $-18{ }^{\circ} \mathrm{C}$, were activated using nutrient agar plates at $35^{\circ} \mathrm{C}$ for $24 \mathrm{~h}$. Single colonies from the plates were inoculated into $30 \mathrm{~mL}$ nutrient broth in $100 \mathrm{~mL}$ Erlenmeyer flasks. Then, they were cultivated aerobically $(120 \mathrm{rpm})$ at $35^{\circ} \mathrm{C}$ for $24 \mathrm{~h}$ to be used as seed culture for the production of EPSs.

For the screening of EPS producing microorganisms, a medium containing (as $\mathrm{g} \mathrm{L}^{-1}$ ); glucose 10 , yeast extract $5, \mathrm{~K}_{2} \mathrm{HPO}_{4} 1.5$ and $\mathrm{MgSO} 4.7 \mathrm{H}_{2} \mathrm{O} 1$ was prepared. Unless otherwise mentioned, production experiments were conducted in $100 \mathrm{~mL}$ Erlenmeyer flasks containing $30 \mathrm{~mL}$ medium. The $\mathrm{pH}$ of the medium was adjusted to 7.0 prior to sterilization at $121{ }^{\circ} \mathrm{C}$ for $15 \mathrm{~min}$. Then, the flasks were inoculated with $5 \%$ fresh cultures (having 2.0 optical density at $600 \mathrm{~nm}$ ) and incubated at 35 ${ }^{\circ} \mathrm{C}$ on a shaking incubator for $24 \mathrm{~h}$. EPSs produced by the isolates were extracted as described below and the amounts of total sugars were determined using phenol-sulfuric acid method (Dubois et al 1956). In screening experiments, Bacillus sp. ZBP4 isolate has produced the highest amount of EPS. Hence, it has been selected for further studies. This bacterium was previously isolated from a soil sample taken from the potato cultivation field and identified as Bacillus subtilis ZBP4 based on 16S rDNA sequence analysis. The sequence is available in GenBank (Acc No. KX811594) (Avci et al 2017).

\subsection{Preparation of molasses}

Raw molasses was diluted with deionized water to a ratio of 1:1 $\left(\mathrm{w} \mathrm{w}^{-1}\right)$. After the adjustment of $\mathrm{pH}$ to 4.0 using $2 \mathrm{~N} \mathrm{HCl}$, it was boiled for the decantation of impurities. Upon cooling, it was first filtered through regular filter paper followed by centrifugation at $9000 \mathrm{rpm}$ for $10 \mathrm{~min}$. The resulting supernatant was used as substrate for EPS production. 


\subsection{Production of EPS from molasses}

A basal medium was prepared which contained; molasses $40 \mathrm{~g}$, yeast extract $5 \mathrm{~g}, \mathrm{~K}_{2} \mathrm{HPO}_{4} 1.5 \mathrm{~g}$ and $\mathrm{MgSO}_{4} \cdot 7 \mathrm{H}_{2} \mathrm{O} 1 \mathrm{~g}$ in $1000 \mathrm{~mL}$ of deionized water. Initial $\mathrm{pH}$ of the medium was adjusted to 7.0 , except $\mathrm{pH}$ experiments. Five percent $\left(\mathrm{v} \mathrm{v}^{-1}\right)$ fresh seed culture having optical density of 2.0 (at $600 \mathrm{~nm}$ ) was used to inoculate flasks. The effect of temperature on the EPS production was determined by incubating the bacterium in the basal medium at varying temperatures ranging from 30 to $45{ }^{\circ} \mathrm{C}$ on a shaking incubator at $120 \mathrm{rpm}$ for 24 . In order to determine the effect of $\mathrm{pH}$ on the production of EPSs, initial $\mathrm{pH}$ of basal media were adjusted to different $\mathrm{pH}$ values between 4.0 and 9.0 by using either $2 \mathrm{~N} \mathrm{HCl}$ or $2 \mathrm{~N} \mathrm{NaOH}$. Incubations for $\mathrm{pH}$ experiments were carried out at $35^{\circ} \mathrm{C}$ on a shaking incubator at $120 \mathrm{rpm}$ for $24 \mathrm{~h}$. For the determination of the effect of substrate concentration, basal media were prepared using molasses at concentrations ranging from 10 to $60 \mathrm{~g} \mathrm{~L}^{-1}$ and the $\mathrm{pH}$ was adjusted to 7.0. The bacterium was grown in these media at $35{ }^{\circ} \mathrm{C}$ on a shaking incubator at $120 \mathrm{rpm}$ for 24 $\mathrm{h}$. The effect of nitrogen sources was studied by replacing yeast extract from the basal medium with ammonium sulfate, tryptone, and peptone $\left(5 \mathrm{~g} \mathrm{~L}^{-1}\right)$ and one experiment was also performed without any nitrogen source. Selected carbon sources (starch, lactose, mannitol, glucose, whey) were also tested separately by replacing the molasses from the basal medium. The concentration of each carbon source was $30 \mathrm{~g} \mathrm{~L}^{-1}$. In the experiments regarding the effects of nitrogen sources, the initial $\mathrm{pHs}$ of the media were adjusted to 5.0 by using $2 \mathrm{~N} \mathrm{HCl}$, and all incubations were conducted with shaking at 120 rpm, $45^{\circ} \mathrm{C}$ for $24 \mathrm{~h}$.

Finally, an experiment was conducted at the optimized conditions where a medium containing; molasses $60 \mathrm{~g}$, tryptone $5 \mathrm{~g}, \mathrm{~K}_{2} \mathrm{HPO}_{4} 1.5 \mathrm{~g}$ and $\mathrm{MgSO}_{4} \cdot 7 \mathrm{H}_{2} \mathrm{O} 1 \mathrm{~g}$ in $1000 \mathrm{~mL}$ of deionized water, was prepared with an initial $\mathrm{pH}$ of 5.0. The bacterium was incubated in this medium at $45^{\circ} \mathrm{C}$ for $24 \mathrm{~h}$ on a shaking incubator at $120 \mathrm{rpm}$. Sample was taken at the end of the incubation and subjected to analysis of EPS.

\subsection{EPS extraction}

EPS extraction was done according to Koçberber \& Dönmez (2008) with some modifications. Briefly, $5 \mathrm{~mL}$ sample was boiled for $15 \mathrm{~min}$ to inactivate enzymes in the fermentation broth. Upon cooling, TCA $\left(4 \% ; \mathrm{w} \mathrm{V}^{-1}\right)$ was added into the sample, and subsequently vortexed and centrifuged at $9000 \mathrm{rpm}$, $4{ }^{\circ} \mathrm{C}$ for $30 \mathrm{~min}$ to precipitate proteins. Supernatant was transferred into a clean tube and the same volume of $99.5 \%$ cold ethanol (at $4{ }^{\circ} \mathrm{C}$ ) was added. The mixture was stored at $4{ }^{\circ} \mathrm{C}$ overnight. Then it was centrifuged at $9000 \mathrm{rpm}, 4{ }^{\circ} \mathrm{C}$ for $30 \mathrm{~min}$ to precipitate the EPS. Supernatant was removed and pellets containing the EPSs were dissolved in $1 \mathrm{~mL}$ of deionized water and used as crude EPSs.

\subsection{Determination of EPS amount}

Total sugars were determined using phenol-sulfuric acid method described by Dubois et al (1956) using a glucose standard curve. Same samples were also subjected to reducing sugar analysis by 3,5-dinitrosalycylic acid (DNS) method (Miller 1959) to detect trace sugars in the samples and the results were subtracted from the total sugars determined by phenol-sulfuric acid method.

\subsection{Statistical analysis}

All the experiments were conducted at least in duplicate and values as mean \pm SD were reported. Duncan's Multiple Range Test was applied for the determination of the significance among the means $(\mathrm{P}<0.05)$.

\section{Results and Discussion}

\subsection{Screening of Bacillus strains for EPS production}

Twelve Bacillus strains that were isolated from soil and some food samples were screened for their EPS productions. Two of the isolates did not produce EPSs and the rest of them produced varying amounts ranging from 13.4 to $143.1 \mathrm{mg} \mathrm{L}^{-1}$ (Table 1). EPS producing bacteria formed mucoid colonies on agar media that was also an indication of the formation of EPSs (Figure 1). The best EPS producer, Bacillus sp. ZBP4, was used for the production of EPSs from molasses. 
Table 1- Production of exopolysaccharides by Bacillus strains isolated from various sources from glucose; the initial pHs of the media were adjusted to 7.0 and incubations were performed on a shaking incubator $(120 \mathrm{rpm})$ at $35^{\circ} \mathrm{C}$ for $24 \mathrm{~h}$

\begin{tabular}{lc}
\hline Bacteria & $\begin{array}{c}\text { Amount of EPS } \\
\left(m g ~^{-1}\right)\end{array}$ \\
\hline Bacillus sp. BAST2 & 13.4 \\
Bacillus sp. BMZE2 & 43.5 \\
Bacillus sp. BMZE3 & 81.9 \\
Bacillus sp. BMZE4 & 39.8 \\
Bacillus sp. ZGT1 & 0.0 \\
Bacillus sp. ZGT3 & 40.0 \\
Bacillus sp. ZGT5 & 0.0 \\
Bacillus sp. ZGT9 & 48.8 \\
Bacillus sp. ZBP4 & 143.1 \\
Bacillus sp. ZBP10 & 99.2 \\
Bacillus sp. GIT2 & 48.5 \\
Bacillus sp. BAT3 & 72.2 \\
\hline
\end{tabular}

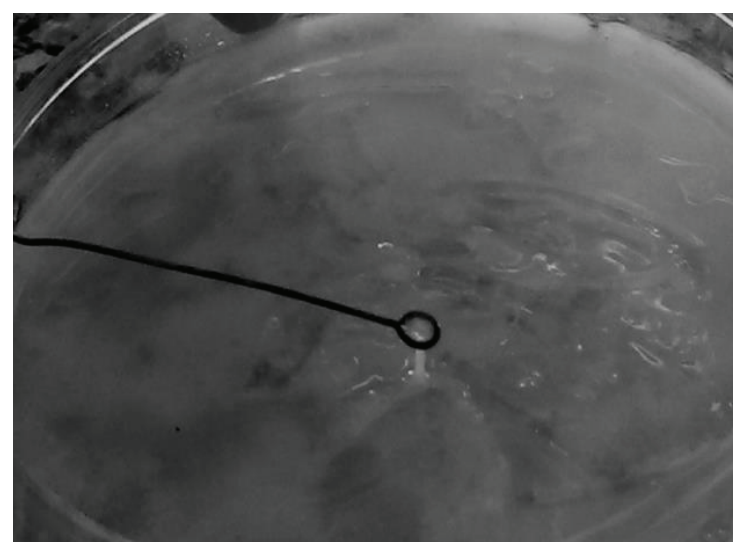

Figure 1- Mucoid appearance of exopolysaccharide (EPS) produced by Bacillus sp. ZBP4 on nutrient agar

\subsection{Effect of growth parameters on EPS production}

\subsubsection{Effect of substrate concentration on EPS production}

Optimization of the growth parameters effecting the EPS production have been investigated using beet molasses as carbon source which contained $46.3 \%\left(\mathrm{w} \mathrm{W}^{-1}\right)$ total sugars. Initially, optimal molasses concentration was determined using
10-60 $\mathrm{g} \mathrm{L}^{-1}$ molasses in the basal medium. The lowest EPS production has been detected at $10 \mathrm{~g}$ $\mathrm{L}^{-1}$ concentration which was $68 \mathrm{mg} \mathrm{L}^{-1}$. Significant increases in EPS production have been observed with increasing concentrations $(\mathrm{P}<0.05)$ and it reached its maximum (426 $\left.\mathrm{mg} \mathrm{L}^{-1}\right)$ at $60 \mathrm{~g} \mathrm{~L}^{-1}$ molasses concentration which corresponds to 27.8 $\mathrm{g} \mathrm{L}^{-1}$ total sugars (Figure 2). It has been indicated that EPS production was stimulated by the excess of carbohydrate in the medium and limitation of carbon sources diminishes EPS synthesis (Van GeelSchutten et al 1998; De Vuyst \& Degeest 1999). A number of reported researches concerning the effect of substrate concentration suggest that optimum substrate concentration varies depending on the individual microorganism. For instance, Çelik et al (2008) tested the effect of substrate concentration on EPS production by Pseudomonas aeruginosa G1 and Pseudomonas putida G12 using xylose and found the maxima as $368 \mathrm{mg} \mathrm{L}^{-1}$ and $262 \mathrm{mg} \mathrm{L}^{-1}$ at $3 \%\left(\mathrm{w} \mathrm{v}^{-1}\right)$ and $2 \%$ concentrations, respectively. Halomonas anticariensis produced EPS better at $1 \%\left(\mathrm{w} \mathrm{v}^{-1}\right)$ glucose concentration (Mata et al 2006). Bacillus licheniformis produced maximum EPS ( $\left.\sim 600 \mathrm{mg} \mathrm{L}^{-1}\right)$ with $2 \%$ sucrose $\left(\mathrm{w} \mathrm{v}^{-1}\right)$ (Larpin et al 2002). On the other hand, there are microorganisms requiring much higher substrate concentrations, such as Rhizobium rodiobacter which produced $2834 \mathrm{mg} \mathrm{L}^{-1}$ EPS on $10 \%$ whey (Zhou et al 2014).

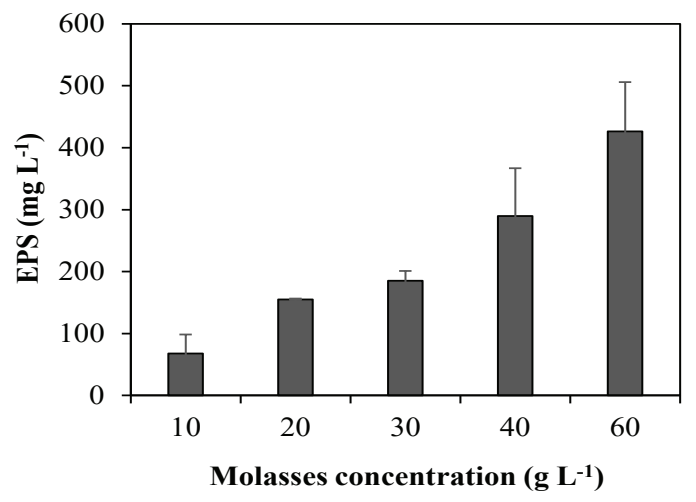

Figure 2- Production of exopolysaccharide by Bacillus sp. ZBP4 at varying molasses concentrations; the initial $\mathrm{pHs}$ of the media were adjusted to 7.0 and incubations were performed on a shaking incubator $(120 \mathrm{rpm})$ at $35^{\circ} \mathrm{C}$ for $24 \mathrm{~h}$ 
Production of EPS was also determined during longer incubation periods and a drastic decrease (ca $30-40 \%$ ) has been detected at $48 \mathrm{~h}$ and $72 \mathrm{~h}$ of the incubation compared with the production at $24 \mathrm{~h}$ (data not shown). The decrease in EPS yield after a certain incubation time is due to the activity of glycohydrolases secreted by the microorganisms into fermentation medium which catalyze the degradation of EPS (Li et al 2014).

\subsubsection{Effect of temperature on EPS production}

Temperature for EPS biosynthesis is crucial (Lui et al 2009). Thus, the impact of temperature on EPS production was determined by incubating the bacterium in the basal medium at temperatures ranging between 30 and $45{ }^{\circ} \mathrm{C}$. Figure 3 depicts the EPS amounts produced at varied temperatures and growth of the bacterium which were given as optical density $\left(\mathrm{OD}_{600}\right)$ measured by using a spectrophotometer. Interestingly, temperatures beyond the optimum growth temperature $\left(33-35{ }^{\circ} \mathrm{C}\right)$ of Bacillus sp. ZBP4 promoted the production of EPS, and the production became the lowest at temperatures 35 and $37^{\circ} \mathrm{C}$ where the strain ZBP4 grows well. Means of the values determined at different temperatures were statistically different $(\mathrm{P}<0.05)$. Various temperature dependencies were reported in the literature. For instance, Wang et

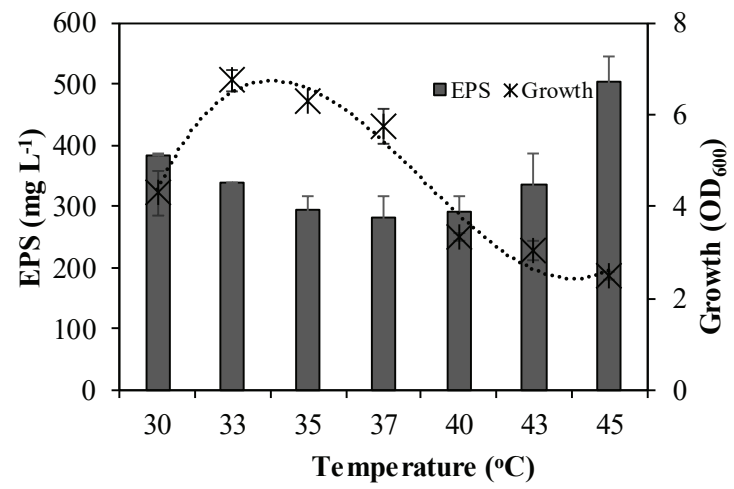

Figure 3-Growth and exopolysaccharide production by Bacillus sp. ZBP4 at different temperatures; the initial $\mathrm{pH}$ of the media were adjusted to 7.0 and incubations were performed on a shaking incubator $(120 \mathrm{rpm})$ for $24 \mathrm{~h}$ al (2011) obtained maximum amount of EPS with Paenibacillus sp. TKU023 at $37{ }^{\circ} \mathrm{C}$ while having lower yields at low temperatures which is not in accord with our findings. Lui et al (2009) reported the best EPS production temperature for Paenibacillus polymyxa as $24{ }^{\circ} \mathrm{C}$. It is known that EPSs help the cell in protecting it from stress conditions such as temperature, $\mathrm{pH}$, and light intensity, thus its production is a direct response to environmental conditions (Donot et al 2012). In our study, higher production rates of EPSs at lower or higher temperatures can be attributed to that phenomenon because Bacillus sp. ZBP4 produced the maximum amount of EPS at $45{ }^{\circ} \mathrm{C}$, which is reasonably higher than the optimum growth temperature of the bacterium.

\subsubsection{Effect of $p H$ on EPS production}

The $\mathrm{pH}$ of the medium is an important parameter affecting the cell membrane and structure thereby nutrient uptake and EPS production are also influenced (Liu et al 2009). In this regard, EPS production was performed at different $\mathrm{pH}$ values and the results showed that EPS biosynthesis has been significantly affected by the $\mathrm{pH}$ of the medium $(\mathrm{P}<0.05)$ (Figure 4). The highest EPS production was achieved at $\mathrm{pH} 5.0$ and it decreased with increasing $\mathrm{pH}$ values. $\mathrm{pH} 4.0$ and $\mathrm{pH} 9.0$ resulted in the lowest

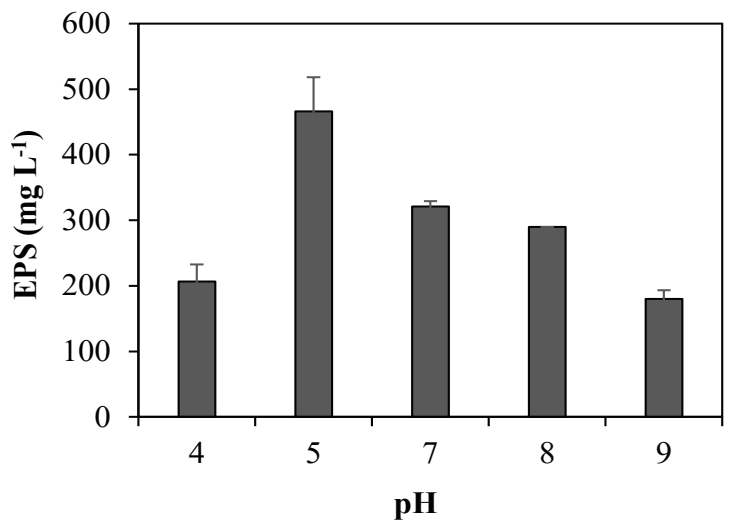

Figure 4- Effect of initial medium pH on the production of exopolysaccharide by Bacillus sp. ZBP4; incubations were performed on a shaking incubator $(120 \mathrm{rpm})$ at $35^{\circ} \mathrm{C}$ for $24 \mathrm{~h}$ 
EPS productions. Levansucrase is an extracellular enzyme that catalyzes the production of levan from sucrose and it was reported that it is produced when the $\mathrm{pH}$ of the medium is acidic (Castillo \& Lopez-Mungia 2004; Donot et al 2012). That can be possible explanation why our strain had produced EPS maximally at pH 5.0. Moreover, as mentioned above, harsh conditions forces microorganisms to secrete EPS for protection.

The medium composition affects the EPS secretion by microorganisms to a great extent (Çelik et al 2008). Carbon sources display different effect on catabolic repression and secondary metabolisms (Liu et al 2009). In this study, effects of different carbon sources on EPS production were tested by replacing molasses in the basal medium with glucose, lactose, starch, whey and mannitol. Bacillus sp. ZBP4 produced EPS on all the carbon sources tested in varying amounts. Yet, molasses was the best carbon source followed by whey and glucose which resulted in reasonably higher yields than the other carbon sources tested. Levan is synthesized by the enzyme levansucrase from sucrose (Donot et al 2012). Since the major sugar constituent of molasses is sucrose, most probably the stain ZBP4 is producing levan. However, when pure sucrose was used, the production of EPS decreased dramatically. It can be suggested that the amino acids found in molasses significantly promoted the production. The same case was also seen with whey which contains lactose and proteins. EPS production was doubled when whey was used compared with lactose. Similar results were obtained by Abdul Razack et al (2013) who produced EPS by B. subtilis from cane molasses and sucrose and they found 4.86 and 2.98 g L $\mathrm{L}^{-1}$ EPSs, respectively. As being economically viable and fermentable by many microorganisms, either cane or beet molasses were successfully used in a number of studies (Göksungur et al 2004; Abdel-Aziz et al 2012; Sirajunnisa et al 2012; Abdul Razack et al 2013). Mannitol gave the weakest yields followed by starch and lactose.

Several nitrogen sources (tryptone, peptone, yeast extract, ammonium sulfate) were tested in order to find out the best one for EPS production by Bacillus sp. ZBP4 (Table 2). Ammonium sulfate that was used as inorganic nitrogen source led to decrease in EPS synthesis. Similarly, some researchers have also found decreased EPS yields with inorganic nitrogen compounds and it was proposed that some amino acids cannot be synthesized from inorganic nitrogen sources (Abdul Razack et al 2013). Amongst the organic nitrogen sources used, tryptone was found as an excellent ingredient with which $974 \pm 72 \mathrm{mg} \mathrm{L}^{-1}$ EPS was obtained while it was $525 \pm 2 \mathrm{mg} \mathrm{L}^{-1}$ when the yeast extract was used. Peptone seemed to be ineffective on EPS production which gave almost the same amount of EPS when there is no nitrogen supplement in the medium.

Table 2- Effects of carbon and nitrogen sources on the production of exopolysaccharides by Bacillus sp. ZBP4; the initial pH of the media were adjusted to 5.0 and all the incubations were carried out on a shaking incubator $(120 \mathrm{rpm})$ at $45^{\circ} \mathrm{C}$ for $24 \mathrm{~h}$

\begin{tabular}{llll}
\hline $\begin{array}{l}\text { Carbon } \\
\text { sources }\end{array}$ & $\begin{array}{l}\text { EPS } \\
\left(m g L^{-1}\right)\end{array}$ & Nitrogen sources & $\begin{array}{l}\text { EPS } \\
\left(m g L^{-1}\right)\end{array}$ \\
\hline Glucose & $450^{\mathrm{d}^{*}} \pm 10$ & Ammonium sulfate & $\begin{array}{l}388^{\mathrm{a}} \pm 67 \\
974^{\mathrm{c}} \pm 72\end{array}$ \\
Starch & $171^{\mathrm{b}} \pm 42$ & Tryptone & $525^{\mathrm{b}} \pm 2$ \\
Lactose & $220^{\mathrm{bc}} \pm 9$ & Yeast extract & $448^{\mathrm{ab}} \pm 42$ \\
Whey & $452^{\mathrm{d}} \pm 25$ & Peptone & $432^{\mathrm{ab}} \pm 19$ \\
Mannitol & $103^{\mathrm{a}} \pm 22$ & Without nitrogen & \\
Sucrose & $243^{\mathrm{bc}} \pm 21$ & & \\
Molasses & $505^{\mathrm{d}} \pm 41$ & & \\
\hline
\end{tabular}

*, means with different letters in each column are significantly different for each sample $(\mathrm{P}<0.05)$; ${ }^{* *}$, only molasses was used in the medium without nitrogen supplementation

\section{Conclusions}

EPS production by Bacillus sp. ZBP4 was investigated using molasses as substrate. The effects of substrate concentration, $\mathrm{pH}$, temperature, and carbon and nitrogen sources on the production of EPSs were determined. The strain produced the highest amount of EPS in the medium having an initial $\mathrm{pH}$ of 5.0, at $60 \mathrm{~g} \mathrm{~L}^{-1}$ molasses concentration, at $45^{\circ} \mathrm{C}$ in $24 \mathrm{~h}$. Use of tryptone as nitrogen source has markedly enhanced the secretion of EPSs. The microorganism produced $1071 \mathrm{mg} \mathrm{L}^{-1}$ EPS under the optimized conditions. The results showed that 
the isolate Bacillus sp. ZBP4 can be good candidate for the production of EPSs and it was able to utilize molasses both as carbon and nitrogen sources. However, there is a need for more studies in this topic.

\section{Acknowledgements}

This work is part of the 2014-50-01-013 project financially supported by the Sakarya University Scientific Research Projects Units. We express our sincerest gratitude to them for their support Sakarya University Scientific Research Projects Units. The authors thank İnci CANTIK (Sakarya University, Department of Food Engineering) for performing statistical analysis.

\section{References}

Abdel-Aziz S M, Hamed H A, Mouafi F E \& Gad A S (2012). Acidic pH-shock induces the production of an exopolysaccharide by the fungus Mucor rouxii: Utilization of beet-molasses. New York Science Journal 5(2): 52-61

Abdul Razack S, Velayutham V \& Thangavelu V (2013). Medium optimization for the production of exopolysaccharide by Bacillus subtilis using synthetic sources and agro wastes. Turkish Journal of Biology 37: $280-288$

Avc1 A, Cagri-Mehmetoglu A \& Arslan D (2017). Production of antimicrobial substances by a novel Bacillus strain inhibiting Salmonella Typhimurium. LWT Food Science and Technology 80: 265-270

Castillo E \& Lopez-Mungia A (2004). Synthesis of levan in water-miscible organic solvents. Journal of Biotechnology 114(1-2): 209-217

Çelik G Y, Aslım B \& Beyatli Y (2008). Characterization and production of the exopolysaccharide (EPS) from Pseudomonas aeruginosa G1 and Pseudomonas putida G12 strains. Carbohydrate Polymers 73: 178182

De Vuyst L \& Degeest B (1999). Heteropolysaccharides from lactic acid bacteria. FEMS Microbiology Reviews 23: 153-177

Donot F, Fontana A, Baccou J C \& Galindo S S (2012). Microbial exopolysaccharides: main examples of synthesis, excretion, genetics and extraction. Carbohydrate Polymers 87: 951-962
Dubois M, Gilles K A, Hamilton J K, Rebers P A \& Smith F (1956). Colorimetric method for determination of sugars and related substances. Analytical Chemistry 28: $350-356$

Fang Y, Ahmed S, Liu S, Wang S, Lu M \& Jiao Y (2013). Optimization of antioxidant exopolysaccharides production by Bacillus licheniformis in solid state fermentation. Carbohydrate Polymers 98: 1377-1382

Freitas F, Alves V D \& Reis M A M (2011). Advances in bacterial exopolysaccharides: From production to biotechnological applications. Trends in Biotechnology 29: 388-398

Göksungur Y, Uçan A \& Güvenç U (2004). Production of pullulan from beet molasses and synthetic medium by Aureobasidium pullulans. Turkish Journal of Biology 28: $23-30$

Koçberber K N \& Dönmez G (2008). Environmental conditions affecting exopolysaccharide production by Pseudomonas aeruginosa, Micrococcus sp. and Ochrobactrum sp. Journal of Hazardous Materials 154: 1019-1024

Kumar T (2012). Microbial extracellular polymeric substances production, isolation and applications. IOSR Journal of Pharmacy 2(2): 276-281

Larpin S, Sauvageot N, Pichereau V, Laplace J M \& Auffray Y (2002). Biosynthesis of exopolysaccharide by a Bacillus licheniformis strain isolated from ropy cider. International Journal of Food Microbiology 77: 1-9

Li W, Ji J, Chen X, Jiang M, Rui X \& Dong M (2014). Structural elucidation and antioxidant activities of exopolysaccharides from Lactobacillus helveticus MB2-1. Carbohydrate Polymers 102: 351-359

Liu J, Luo J, Ye H, Sun Y, Lu Z \& Zeng X (2009). Production, characterization and antioxidant activities in vitro of exopolysaccharides from endophytic bacterium Paenibacillus polymyxa EJS-3. Carbohydrate Polymers 78: 275-281

Mata J A, Béjar V, Llamas I, Arias S, Bressollier P, Tallon R, Urdaci M C \& Quesada E (2006). Exopolysaccharides produced by the recently described halophilic bacteria Halomonas ventosae and Halomonas anticariensis. Research in Microbiology 157: 827-835

Miller G L (1959). Use of dinitrosalycylic acid reagent for determination of reducing sugar. Analytical Chemistry 31: $662-666$

Öztürk S, Aslım B, Suludere B \& Tan S (2014). Metal removal of cyanobacterial exopolysaccharides by 
uronic acid content and monosaccharide composition. Carbohydrate Polymers 101: 265-271

Salehizadeh H \& Shojaosadati S A (2003). Removal of metal ions from aqueous solution by polysaccharide produced from Bacillus firmus. Water Research 37(17): 4231-4235

Shih I, Chen L D \& Wu J Y (2010). Levan production using Bacillus subtilis natto cells immobilized on alginate. Carbohydrate Polymers 82(1): 111-117

Singh R P, Shukla M K, Mishra A, Kumari P, Reddy C R $K$ \& Jha B (2011). Isolation and characterization of exopolysaccharides from seaweed associated bacteria Bacillus licheniformis. Carbohydrate Polymers 84: 1019-1026

Sirajunnisa A, Vijayagopal V \& Viruthagiri T (2012). Effect of synthetic carbon substrates and cane molasses, an agro waste, on exopolysaccharide production by $P$. fluorescens. International Journal of Science and Engineering Applications 1(1): 60-66

Tallon R, Bressollier P \& Urdaci M C (2003). Isolation and characterization of two exopolysaccharides produced by Lactobacillus plantarum EP56. Research in Microbiology 154: 705-712
Van Geel-Schutten G H, Flesch F, ten Brick B, Smith M R \& Dijkhuizen L (1998). Screening and characterization of Lactobacillus strains producing large amounts of exopolysaccharide. Applied Microbiology and Biotechnology 50: 697-703

Wang C L, Huang T H, Liang T W, Fang C Y, San-Lang \& Wang S L (2011). Production and characterization of exopolysaccharides and antioxidant from Paenibacillus sp. TKU023. New Biotechnology 28(6): 559-565

Welman A D, Ian S \& Maddox I S (2003). Exopolysaccharides from lactic acid bacteria: Perspectives and challenges. Trends in Biotechnology 21(6): 269-274

Yilmaz M, Yuvali Celik G, Aslim B \& Onbasili D (2012). Influence of carbon sources on the production and characterization of the exopolysaccharide (EPS) by Bacillus sphaericus 7055 strain. Journal of Polymers and Environment 20: 152-156

Zhou F, Wu Z, Chen C, Han J, Ai L \& Guo B (2014). Exopolysaccharides produced by Rhizobium radiobacter $\mathrm{S} 10$ in whey and their rheological properties. Food Hydrocolloids 36: 362-368 